\title{
RESPONSIBLE DEVELOPMENT FOR MANAGING A SUSTAINABLE FUTURE
}

\section{Dumitru Alexandru BODISLAV ${ }^{a^{*}, \text { Florina BRAN }}{ }^{b}$, Mihai DINU $^{c}$, Raluca Iuliana GEORGESCU ${ }^{d}$}

${ }^{a, b, c, d}$ Bucharest University of Economic Studies, Romania

\begin{abstract}
This study is being written to better understand the process of developing responsible development in order to promote a long-term future. The purpose of this article is to present a clear and straightforward view of how the economy should operate, with the final objective of long-term sustainability and evolutionary progress.
\end{abstract}

KEYWORDS: evolution, stability, sustainable development

DOI: 10.24818/IMC/2021/02.13

\section{INTRODUCTION}

The willingness to experience the repercussions of one's conduct, especially for any negative judgments, acts, and neglect, is the source of responsibility. The sense of responsibility is determined by awareness of the prohibitions and regulations that govern a certain location and time. Compliance and liability are inextricably intertwined. In theory, irresponsibility, such as failing to meet a commitment, results in moral, legal, political, or other consequences. The majority of the time, however, the obligation includes a moral or legal component. Punishments, guilt, repentance, condemnation, expulsion, and loss of trust are all examples of the repercussions of breaking legal norms, moral standards, and religious precepts in a given culture. A judgment, a judicial decision, or an acknowledgment is required for a violation of the law or regulation (recognition). Unfortunately, despite knowing the negative repercussions, an increasing number of individuals are reckless. The rise in the number of irresponsible persons can be attributed to a variety of subjective factors. For starters, they are limited in their freedom as a result of their responsibilities. Second, they live in liberal societies that provide individuals with the greatest level of liberty. In actuality, however, this liberty is severely limited. As a result, the truth of freedom is declared. The character of neoliberal democracy has objective reasons as well.

\section{RESPONSIBILITY AND EVOLUTION}

Until recently, persons were held accountable for what had already occurred as a result of their own actions, i.e. the real consequences. They are more responsible for what could happen, that is, for potential or hypothetical outcomes (Sârbu et al., 2021). As a result, the potential for duty is established in addition to the actual obligation. For some reason, it makes individuals feel better when they are in charge of what could happen to their guilt in the future. However, such a promise to the future is meaningful only if the implications can be forecast with a high degree of certainty within the time frame available (Rădulescu et al., 2021). Accurate prediction is impossible even in the near future in today's society, when statistical laws, chaos, casuistry, and repercussions play a growing role (Bodislav et al., 2020). More and more individuals are participating in particular acts

\footnotetext{
*Corresponding author. E-mail address: alex.bodislav@ase.ro
} 
and decision-making processes where democracy and collaboration are strongly established (Profiroiu et al., 2020). As a result, the outcomes of people's decisions and acts are becoming more the product of communal effort, and the offenders are becoming increasingly unknown. Individual and unique accountability eventually fades away as a result. As a result, the sense of collective and anonymous responsibility grows. Abstract and indirect responsibility replaces tangible and direct accountability when people make more decisions (Angheluță et al., 2019). And when it's unclear who is genuinely accountable for anything - as in the case of a collective perpetrator, i.e. an anonymous and abstract entity - it encourages carelessness and even impunity (Faggianelli et al., 2018). The more jointly responsible they are, the more false and hollow their accountability becomes. In the end, this means that no one is responsible for anything because everyone is accountable for everything (Burlacu et al., 2019). People are increasingly seeking protection from their own duty, guilt, and punishment by transferring their blame and responsibility on other people or objects (Carra, C. et al., 2018). As a result, subjective responsibility, or human and personal responsibility, progressively transforms into objective accountability. Things, of course, are not to blame and have no repercussions. Floods, for example, are said to be caused by guards in bad condition (dams, dams, etc.). The major offender, though, is the person who developed the wrong item and failed to manage the project properly. Another example: traffic accidents are caused by trees on highways, not by drivers who are inexperienced or have a poor comprehension of driving conditions.

This obligation has become abstract, individual - communal, real - unreal, and direct - indirect in today's world. As a result, accountability becomes even more impunity, and the notion of accountability begins to lose its meaning.

Simultaneously, irresponsibility is becoming increasingly common. People are accustomed to it, regard it as if it were unrelated to them, and generally tolerate recklessness. They not only accept those in power's irresponsibility, but they are also shielded by different immunities that allow them to make judgments that are destructive to society and experiment with live creatures - institutions, organizations, and individuals. The higher one rises in the authority or leadership ladder, the more nameless, hollow, and unpunished one becomes (Sztumski, 2018).

High-ranking members of society who are aware of impunity can make judgments without relying on covert and irresponsible programs that are frequently destructive to the public good and hazardous. Leaders do not want to be held accountable to the public. They believe it is more important to be answerable to God and history, and that this is a huge duty. Because it relates to an imagined or abstract entity, it is an illusory responsibility and a fiction of accountability. One individual bears personal responsibility, obviously, directly, and particularly, when operating in their strictly local context. However, such a restricted and personal duty in time and place has nothing to do with the operation of society as a whole and, in particular, the international community's boundaries.

\section{RESPONSIBILE DEVELOPMENT, STAGE 1 FOR SUSTAINABLE DEVELOPMENT}

When making decisions, responsible development includes aiming to satisfy people's expanding demands while taking into account environmental, social, economic, health, and safety issues:

1. In conformity with the Community's overarching objectives.

2. It satisfies economic, cultural, and educational requirements.

3. Put future-oriented product maintenance and development ahead of current-oriented product maintenance and development.

4. Create as many employment as possible for as many people as possible, and pay them well enough that the employee and his family can fulfill his basic necessities.

5. Conserve as much energy, water, and fossil fuels as feasible. Smart development is one type of responsible development. 
It is now employed in a variety of fields of public life, including as urban planning and economics. In the first scenario, it is such an urbanism that provides the ideal circumstances for entertainment, transportation, administration of administrative service centers, health, and so on for the city's residents. In the second scenario, we're talking about boosting innovation and knowledge to boost economic growth. Instead of "Money makes the world come back," there is now a new sentence: "Knowledge makes the world come back" (Georgescu, 2020). Knowledge is the only natural resource that grows rather than depletes with use. Smart development will very certainly extend to other sectors quickly. The maximal rationalization of the economy and management is a necessary, but not sufficient, prerequisite for responsible and wise growth. As a result, the economy was mathematically rapid for a long period. This allows for the determination of parameters that define the status of economic systems, the creation of mathematical models of the economy, the management of economic processes, and the minimization of production costs through more precise profit and loss calculations. The improvement of the economy is aided by the rationalization of the economy. This entails employing processes, procedures, and equipment that yield the highest financial outcomes while consuming the least amount of capital, labor, energy, and raw materials. The rationalization of the economy has created a paradox: it rationalizes the economy to maximize profits while also changing customers' attitudes and behavior in an illogical way. This paradox exemplifies one of the numerous inconsistencies that characterize the modern economy. This is a common dilemma in the development of a knowledge society. Unfortunately, despite progress and an increase in the number of individuals with higher education, irrationality still outnumbers logic, and stupidity outnumbers wisdom, demonstrating yet another example of societal imbalance. However, we may expect that the tendency of rationalization will eventually triumph over the trend of rationalization, and that the economy, like other aspects of life, will be totally organized. This might be owing to the widespread usage of robots and artificial intelligence. Many experts, including Stephen Hawking, Bill Gates, and Elon Musk, have warned about the perils of AI. They contend that it is not simply about diminishing the need for human labor (people will be replaced by robots) and the resulting negative societal consequences. It even poses a threat to human civilization and the species' survival. First and foremost, this can occur when artificial intelligence has progressed to the point where it can replace all of the functions of the human brain. The current issue is the artificial memory's growth (which must match to the physical brain's memory) and the artificial brain's shrinkage (Bodislav, 2015). Second, when artificial intelligence improves in comparison to human intellect, compatibility difficulties between humans and AI may occur (Bostrom, 2014). This is improbable now, and even if it occurs in the far future, which is regarded hopeful, there is no need to be concerned. However, because, on the one hand, artificial intelligence is fast developing, and on the other hand, the intellect of the human population is rapidly dropping, potentially in development function, this might happen in a shorter period than we originally imagined. Artificial intelligence, however, may be deadly even today if it comes into the hands of government leaders, irresponsible individuals, or even those with mental health issues. A progressive cyber-attack targeting 2.0 people, when artificial intelligence reaches the level of natural intelligence, and 3.0 people, when a person becomes worthless or available to all in the era of the Internet of Things, poses the greatest threat to mankind (Kurzweil, 2014, Sowa, 2015).

\section{SUSTAINABILITY RESULTED FROM DEVELOPMENT FRAMEWORKS}

People have been interested in ecology for a long time, dating back to the early 1970s. As a result, the topic of sustainability has become increasingly essential in terms of ecological balance, affecting people all over the world. Long-term action, long-term outcomes, stability, longevity, balance, and the capacity to establish ideal conditions for anything are all synonyms for meningeal. Sustainability, thanks to environmentalists, relates to societal growth and denotes balance, harmony, and self-sufficiency. Frequently, the phrase "sustainable" is used instead of "sustainable 
development." Some scholars say that this term is useful in social communication since it is fluid and has a wide range of meanings. The term "sustainable" has evolved into a modern instrument for evaluating human activities in a variety of fields. So, if one wants to engage in any activity, one must do so with the intention of ensuring that it will endure not just for the current generation but also for future generations, so we must behave in a balanced, harmonious, and long-term manner. The preservation of balanced social systems, processes, and phenomena, i.e. stable circumstances in the medium and long term, is of great interest to individuals, particularly professionals in diverse professions.

Social systems are distinct from natural systems, although they have some traits. As a result, it is utilized to increase understanding about balance in physics in talks concerning the balance of social systems. Static and dynamic balance are the two forms of balance recognized by physicists. When the sum of all forces acting on a body is zero, it is said to be in static equilibrium. The body then stays calm or travels in a straight path, according to the first principle of dynamics, and balance refers to the physical condition of the body. When the body deviates from its initial location, it vibrates about it for a while before returning to it. The term "balance" thus refers to a natural process.

Sustainable development is defined as the process of keeping a social system in a stable and dynamic state of equilibrium. The idea that balance and harmony are good for human existence and growth has become legislation. Unfortunately, this is another another urban legend that is circulating. Another myth is that the most effective thing we can do is eliminate stress from human life, or that creating a classless society (as in communism) or homogeneous society (as a result of globalization) ensures happiness by eliminating social contradictions and inequalities. people and is most conducive to human development. It ignores the fact that the social system's equilibrium might be good or terrible, beneficial or detrimental. It is determined by the social, historical, and geographic environment, as well as the people's goals and interests, as well as the definition of kindness, which is typically arbitrary and relevant. The balance between good and evil, for example, is negative because good must always triumph over evil.

The cultural history of Europe is founded in the societal demand to preserve balance that has lately evolved in Western civilization. Initially, in Greek and Roman beliefs and philosophies, then in Christian culture, and finally in the ancient natural sciences. Aristotle's ideas dominated European philosophy, Christian theology, classical (divalent) logic, classical Newtonian physics, and even relativism until the twentieth century. The European tradition is defined by the belief that opposing forces must be balanced. As a result, he contends that a balance must be struck between the two. As a result, there is a need to balance social structures, human activities, and the spirit, as well as a search for global calibrating instruments.

People have believed in the balance and health of natural and social systems for generations. Because of its cultural history, this tale has lived on in the minds of many subsequent generations. Despite the fact that current science, philosophy, and personal experience corroborate the anachronism and lack of foundation, dealing with this is tough today. Similarly, humans have believed in the symmetry of the globe for ages, which is likewise an anachronism and a falsehood according to contemporary understanding. The concept of symmetry, on the other hand, still controls in physics, where it regulates a number of essential laws such as energy conservation, momentum, angular momentum, and so on. The symmetry principle is a helpful tool for idealizing the sensory world. Natural occurrences, especially in macroscopic physics, may be explained using mathematical equations in a simple and straightforward method employing this approach (asymmetric phenomena described by inequalities). It's difficult to say if these two assumptions of balance and symmetry, which serve as stereotypes in thinking about the world and in descriptions, are derived from aesthetic preferences or from knowledge of the reality. For example, symmetry and balance, which are considered to be characteristics of beauty, are still used to determine the 
worth or capitalisation of natural forms. It acknowledges, among other things, its look and simplicity in its accuracy.

\section{CONCLUSIONS}

We are now forming a new vision of the world. This world has evolved as a result of physical and social evolution, as well as our ongoing acquisition of new information and life experience. The world has changed dramatically since the 1960s, and this trend is continuing when compared to the age of our planet, which is believed to be around 4.55 billion years. These shifts are linked to more spontaneous, involuntary, and logical human behaviors, owing to human intervention in homeostatic mechanisms that allow natural and social systems to rebalance and maintain sustainability. When these systems fail as a consequence of irresponsible and reckless manipulation, an imbalance occurs, resulting in a variety of violations, including chaos, instability, and broken symmetry. Disrupting the global trend toward equilibrium in natural and social systems appears to be a watershed moment in the world's and humanity's history. To begin with, asymmetry and imbalance pervade in the modern world, which were formerly regarded endless. Everything that is uneven and imbalanced has been positioned as something lovely for quite some time now. Fashion, art, and architecture in our day are defined by asymmetry and instability. This will most likely define future good taste. Despite this evolution, the notion of balance still holds true in many aspects of social life. It's even better when folks utilize it appropriately. The balance between guilt and punishment, for example, is called into question by the law. The penalty must be proportionate to the crime, i.e., it must balance the crime. If this does not occur, the penalty will be deemed unfair. It refers to a variety of balances in economics, including those between labor and wages, supply and demand, income and spending, and so on. The most fundamental topic in economic values is equilibrium, or the form of equilibrium. The economic balance, on the other hand, is an ideal rather than a genuine state. Employers' wages should be lower than employees' since this ensures a profit. Supply must surpass demand in a functioning economy since it is beneficial to prosperity. In reality, the rest is entirely due to bookkeeping. This only applies to the mathematical description of the sensory world. This is nothing more than balance in the actual world, as if it were the third principle of dynamics, which states, in a very simplified public version, that action equals response. Students' assessments in pedagogy must appropriately represent their knowledge, i.e. the quantity of material they possess. However, owing to subjective considerations, such an accurate estimate is nearly never obtainable, and it is never guaranteed even when objective tests are utilized. Such wise justice is simply a pipe dream. The reality is much different, with varying degrees of unfairness, inequity, and imbalance in each scenario.

\section{REFERENCES}

Angheluță, S. P., Burlacu, S., Diaconu, A., \& Curea, C. S. (2019). The Energy from Renewable Sources in the European Union: Achieving the Goals. European Journal of Sustainable Development, 8(5), 57.

Bodislav, D. A. (2015). Sinergia Big Data-Business Intelligence. Soluția construirii indicatorilor relevanți pentru o economie emergentă, Bucharest, RO: ASE Publishing.

Bodislav, D. A., Buzoianu, O. A. C., Burlacu, S., \& Rădulescu, C. V. (2020). Analysis of companies in Romania from the perspective of risk perception and the management needs thereof. Economic Convergence in European Union, 341.

Bostrom, N. (2014) Superintelligence: Path, Dangers, Strategies, Oxford: Oxford University Press.

Burlacu, S., Alpopi, C., Mitriță, M., \& Popescu, M. L. (2019). Sustainable e-Governance and Human Resource Development. European Journal of Sustainable Development, 8(5), 16. 
Carra, C., Burlacu, S., \& Faggianelli, D. (2018). Violence within the Organizations of Health and Medico-Social Sector. A Comparative Analysis of France and Romania. Economics, Management and Financial Markets, 13(3), 185-202.

Faggianelli, D., Burlacu, S., \& Carra, C. (2018). Victimization of Health Professionals in Bucharest Service Relations and Social Work Relationships. Administratie si Management Public, (30), 109-126.

Georgescu, R. I. (2020). Strategii de valorificare a resurseloe naturale in contextul globalizarii, Bucharest, RO: Universitara Publishing.

Kurzweil, R. (2014). Humanity 2.0: The Singularity, Berlin, DE: Lola Books.

Profiroiu, C. M., Bodislav, D. A., Burlacu, S., \& Rădulescu, C. V. (2020). Challenges of Sustainable Urban Development in the Context of Population Growth. European Journal of Sustainable Development, 9(3), 51-51.

Rădulescu, C. V., Ladaru, G. R., Burlacu, S., Constantin, F., Ioanăș, C., Petre, I. L. (2021) Impact of the COVID-19 Pandemic on the Romanian Labor Market. Sustainability 2021, 13, 271. https://doi.org/10.3390/su13010271

Salvioni, D. (2012). Governance, Risk Management and Business Effectiveness in Global Firm, In D. Tipuric, M. Dabic (ed.), Management Governance and Entrepreunership. New Perspectives and Challenges, Darwen, GB: Access Press.

Sarbu, R., Alpopi, C., Burlacu, S., \& Diaconu, S. (2021). Sustainable urban development in the context of globalization and the health crisis caused by the covid-19 pandemic. Les Ulis: EDP Sciences. doi:http://dx.doi.org/10.1051/shsconf/20219201043

Schneider, A. (2015). Reflexivity in sustainability accounting and management: Transcending the economic focus of corporate sustainability. Journal of Business Ethics, vol. 127, no. 3, $525-536$.

Sowa, A. (2015) Humanity 3.0. Internet of Things, retrieved on 4 July 2021, available online at: https://wszystkoconajwazniejsze.pl/ aleksandra-sowa-menschheit-3-0-internet-der-din ge-oderdie-welt-ohne-menschen.

Sztumski, W. (2018) Responsible development and durable development, Ekorozwoju/ Problems of Sustainable Development, vol. 13, no. 1, 113-120. 